\title{
Is It Possible to Use Biodiesel as a Reference Material?
}

\author{
Dalni Malta do E. Santo Filho et al.* \\ Inmetro \\ Brazil
}

\section{Introduction}

Beyond the complex international metrology structure and its conection to what has been applied in Brazil, using Biodiesel as a reference material constitutes an important factor to the growth of metrological services in the energy sector. Such fact is directly related to the national energy matrix. The fuels' market becomes more demanding each day forcing national companies and laboratories to act systematically, aiming towards reliability and traceability of measures, avoiding any potential barriers unrelated to taxes imposed at national products. It is worth mentioning that comercialization of petroleum based products influences many different sectors of the economy, especially transportation, guaranteeing excelence in the provided services or the complete insuficiency of economic growth.

The necessity of working with biofuels with the purpose of diminishing environmental impacts leads to an extremely relevant pondering for a National Metrology Institute. Any country must be aligned with international requirements and must also guarantee a products' quality through laboratory analysis whose major objective is the maintenance of its reliability and the metrological traceability of their measures. Furthermore, in Brazil, for example, biodiesel is one of the most interesting solutions to diminish, or at least stop, diesel oil importation. While motors that use electrical, wind and solar energy do not provide immediate results that prove to be as useful as petroleum, biodiesel has a certain advantage, since there is no need for great modification in diesel motors to be used with, still providing good efficiency (Lyra, 2008).

However, in order to use biodiesel in a motor and not endanger it, it is essential that previous studies need to be done in testing laboratories with the purpose of guaranteeing the products' specification following certain rules kept by a regulatory agency. For this, using certified reference materials in the measure process is of the utmost importance to guarantee metrological traceability to national laboratories. Because of this, apart from tests to analyse whether the fluid is in accordance with standards ISO EN 14214 and ASTM D6751, this chapter has the purpose of approaching the steps in ISO Guide 34 and ISO Guide 35, discussing the project of producing biodiesel as a reference material, such as

\footnotetext{
* José Renato R. Siqueira ${ }^{1}$, Renata Martins H. Borges ${ }^{1}$, Claudio Roberto da C. Rodrigues ${ }^{1}$, Alex Pablo F. Barbosa ${ }^{1}$, José Júlio P. dos Santos Júnior ${ }^{1}$ and Roberto G. Pereira ${ }^{2}$

1 Inmetro, Brazil

2 UFF/TEM/PGMEC/MSG, Brazil
} 
definition of the material candidate, planning the steps for the preparation of the material, the fulfillment of reference material characterization, homogeneity and stability tests, and, as consequence, the emission of a certificate for the reference material with the presentation of the obtained results. This chapter will also present studies of the physical-chemical properties that are able to keep their characteristics for a longer period if some recommendations, presented in this study, are followed.

Such studies can show the recommended time for stocking this kind of reference material and also for how long it can still be used.

\section{Metrology as a tool to assure quality of measurement's results}

Whether it is in an international or national scope, it can be pointed out that harmonizing norms and technical regulations is of extremely important to commercial relations, other than the necessity to invest in proceedings that aim towards quality assurance of commercialized products. Thus, when looking towards guaranteeing products' quality it is appropriate to fit two subjects of the utmost importance to international commerce: metrology and conformity assessment, building the foundation to any system applied to promoting commercial relations, that is, national products with reliability and metrological traceability meeting the requirements of international technical standards and regulations.

According to Hufbauer et al. (2000), the conformity assessment procedures of a certain product consists in any procedure used, direct or indirectly, to evaluate if certain demands regarding standards or technical regulations are taken into account. Apart from that, such procedures include sampling, testing, inspection, evaluation, verification and assessment assurance, registering, accreditation and approval, and combinations of these possibilities. The procedures for conformity assessment are considered essential in regulations related to health, security and environment contributing to the improvements on productivity and efficiency in commerce economy.

Reliability in the measurements' results is essential in the process of decision making regarding adjustment of different products or services. Measurements support quality controls in industrial processes and applied research, with the emphasis on conformity assurance being responsibility of national and international regulations. With this, metrology encloses, among other characteristics, measurement proficiency, result reliability and metrological traceability (Siqueira, 2006). Any laboratory may present proficiency in its measurements if it can present adequate procedures and have qualified technicians to execute calibration and measurement services, apart from installations regarding each service executed. In the same way, any laboratory that judges itself competent may calibrate equipment from other laboratories and issue calibration certificates and/or test reports. However, results from these laboratories, no matter how competent they may be, can be questioned if their equipment was not calibrated and, thus, the traceability chain may not be assured.

Fig. 1 present metrology as essential in assuring commercial relations and its direct relation with the scientific and technological development of a country, apart from its interaction with the normalization processes and accreditation bodies.

According to the International Vocabulary of Metrology (VIM, 2008; JCGM, 2008), the term metrological traceability consists in "property of a measurement result whereby the result can be related to a reference through a documented unbroken chain of calibrations, each contributing to the measurement uncertainty." 


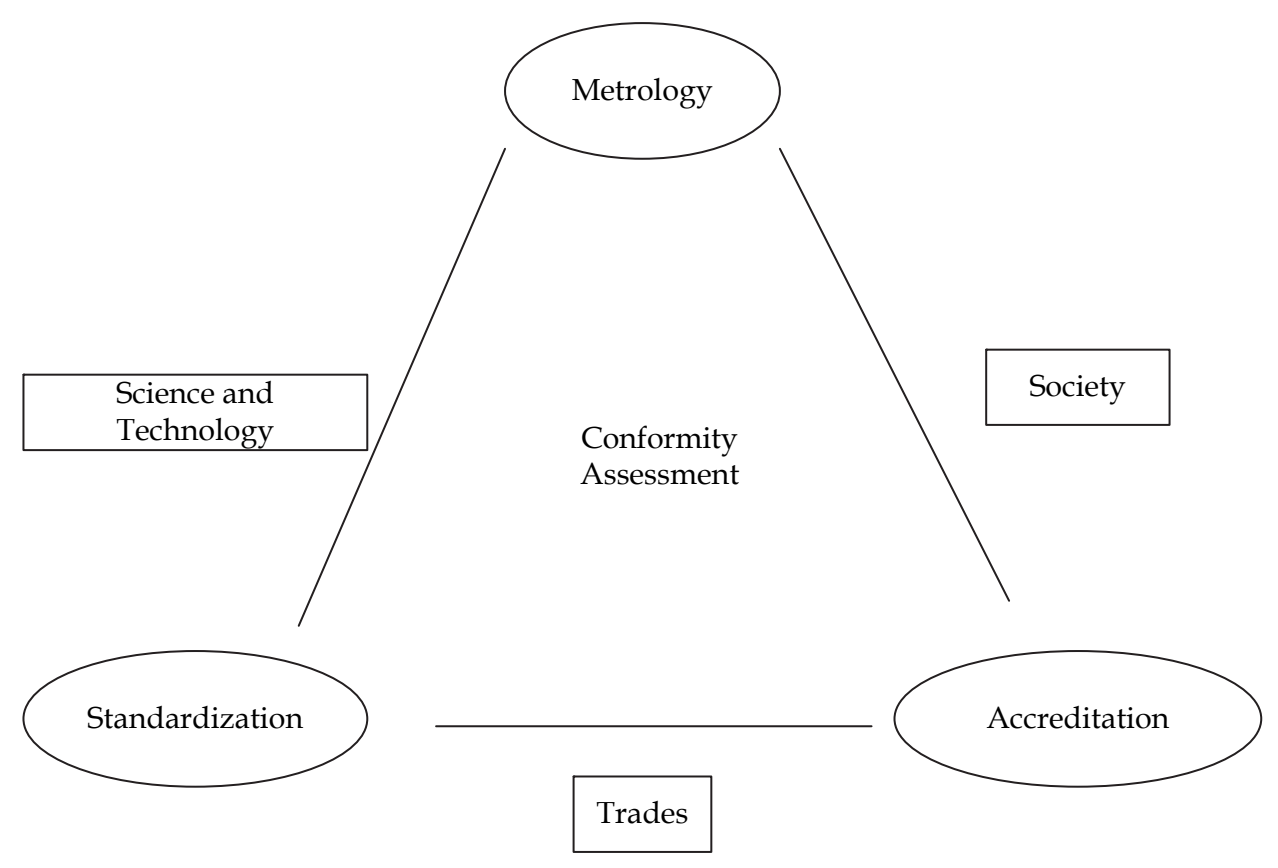

Fig. 1. Support of the conformity assessment infrastructure to economical development (Dennehy, 2006).

The measurement result consists in a "set of quantity values being attributed to a measurand together with any other available relevant information", being usually depicted by one sole measured value and its associated measurement uncertainty. Still according to VIM, the measurement uncertainty characterizes itself as a "non-negative parameter characterizing the dispersion of the quantity values being attributed to a measurand, based on the information used". In this way at each step of the traceability chain, the uncertainty associated to the standards is smaller, implying a crescent technological sophistication, which is the objective of scientific metrology. Fig. 2 shows an example of a established metrological traceability chain.

Based on the exposed facts, the establishment of metrological traceability through an uninterrupted calibration chain is crucial to the operation of equipment and measurement instruments in different sectors of economy. When dealing with test laboratories that analyze biodiesel, the lack of traceability in measurements can generate incorrect conclusions in determining parameters of extreme significance in this products' commercialization, such as, kinematic viscosity and density.

\section{The methodology for preparing reference materials based on ISO guide 34:2009}

Since this chapter analyzes the possibility of developing a reference material using as a matrix the biodiesel that is nationally commercialized, it is of worth to evaluate all parameters regarding production and the possibility of certification of the reference material 


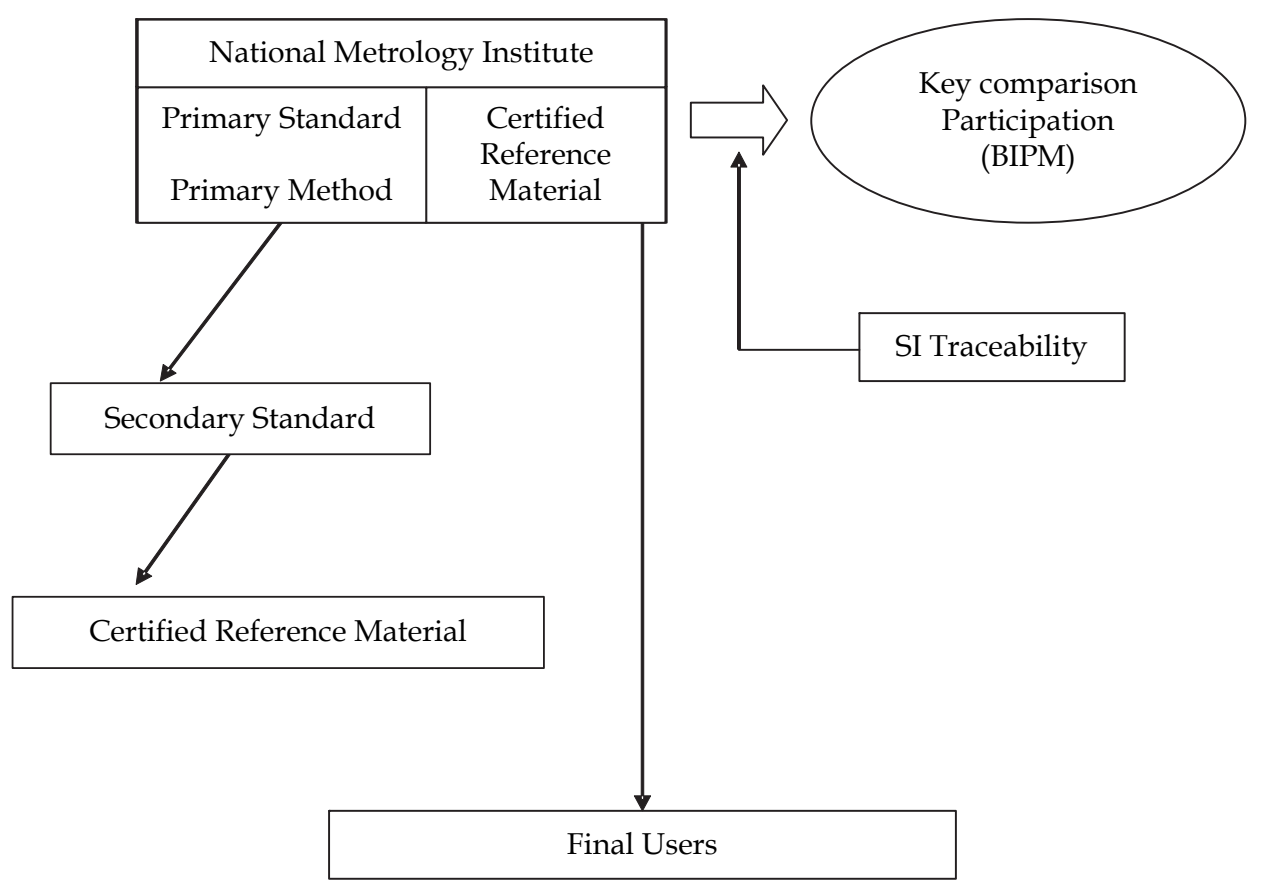

Fig. 2. Example of an established metrological traceability chain (Imai, 2007).

BIPM is the International Bureau of Weights and Measures,

SI is the International System of Units.

using ISO Guide 34. It is worth mentioning that the application of the requirements in ISO Guide 34 take the producer of the reference materials to an in-depth study of the concepts and guidelines of ISO Guide 35:2006, since in the aforementioned are presented the different approaches to be used by the producer in the production planning, attribution of the property value and its uncertainty, to the declaration of metrological traceability and the issue of pertinent information to the user of the reference material.

According to Emons (2006), a reference material consists on a "material sufficiently homogenous and stable regarding one or more specific properties, which have been defined adequate to the purpose of the measurement process." It is worth noting that this new definition is tied to four notes, presented as follows.

Note 1: Reference material is a generic term.

Note 2: Properties may be quantitative or qualitative, for example, identification of substances or species.

Note 3: Usages may include calibration of a measurement system, evaluation of a measurement process, assignment of values to other materials ("assigned values") and quality control.

Note 4: A reference material may be used only for one purpose in a given measurement.

That same publication presents the new definition of certified reference material, which consists of a "reference material, characterized by a metrologically validated method to one 
or more specified properties, accompanied of a certificate which provides a value of the certified property, its associated uncertainty and an established metrological traceability." The new definition also presents three notes, presented as follows.

Note 1: The concept of value includes qualitative attributes such as identity or sequence. Uncertainties for such attributes may be expressed as probabilities.

Note 2: Metrologically valid procedures for production and certification of reference materials are obtained from, among other, ISO Guide 34 and ISO Guide 35.

Note 3: ISO Guide 31 provides guidelines about the content of certificates.

Thus, for an institute to be able to produce a CRM it is necessary to use validated methods and calibrated equipment in order to guarantee the traceability of the measurements and also to thrust the calculation of the estimate of the uncertainty of measurement. Fig. 3 presents the "family" of Reference Materials which may include certified reference materials (CRM) usually represented in smaller quantity due to the difficulties in the process of characterization and certification, the materials known as calibrants (CAL) and, lastly, the quality control materials (QCM). Reference materials such as the ones used for quality control Consist on reference materials used, especially, for statistical control of a measurement process. Calibrants constitute measurement standards used for calibration of a measurement system, being characterized for possessing an established metrological traceability.

Reference Material

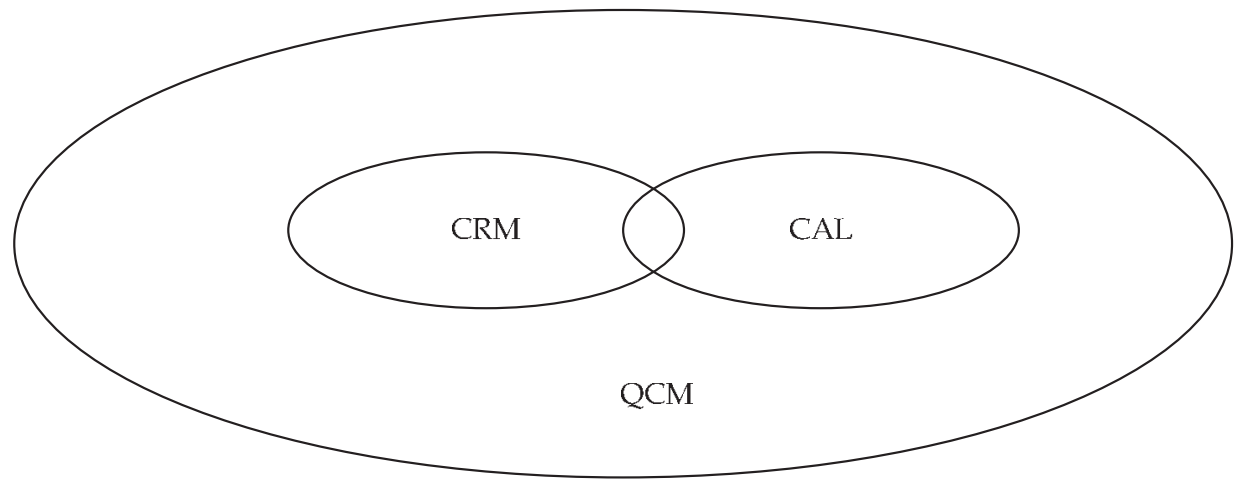

Fig. 3. The "Family" of Reference Materials (Emons, 2006).

It is worth noting that the new definitions were elaborated by the ISO committee that deals with Reference Materials (ISO/REMCO) on the meeting in Genebra, in 2005 (Emons et al., 2005). Such definitions were inserted in the ISO Guide 35 version published in 2006. It is also worth noting that, according to the last annual report made available by ISO, among the 18 members elected to the board responsible for coordinating all ISO, the Brazilian Association for Technical Standards (ABNT) is a part of.

\subsection{Feasibility study for the production of a reference material}

Following ISO Guides 34 and 35, it was possible to establish a viability study for production of a reference material for two physical properties: kinematic viscosity and density. In the aforementioned study samples of beef tallow transesterified with ethanol biodiesel were 
used, since, according with literature data, they would present higher stability since they are a more saturated matrix. As the chapter progresses, the parameter kinematic viscosity will be replaced by viscosity.

\subsection{Accommodation and environmental conditions}

With the purpose of demonstrating the importance of measurements to the energy sector, especially the conformity assessment of the biodiesel which is commercialized nationally, a case study done by Fluids Laboratory (Laflu) from Brazil's National Metrology Institute (Inmetro), which holds the national standards for density and kinematic viscosity, among other quantities.

Laflu is responsible for guaranteeing traceability to measurements in Brazil in density and viscosity. Its competence is confirmed through international interlaboratory comparisons [Maggi et al., 2009] and its services are registered in Appendix C of BIPM (Key Comparison Data Base $[\mathrm{KCDB}])$.

Its installations are such that facilitate the correct accomplishment of tests and calibrations, assuring that environmental conditions do not invalidate results or adversely affect the needed quality for any measurement.

\subsection{Measuring equipment}

As a reference material producer, a National Metrology Institute should follow ISO Guide 34 in combination with ISO/IEC 17025. Considering the measuring equipments, all must be used in compliance with ISO/IEC 17025. Every measurement instrument was calibrated, verified and kept properly. This way, the reference materials produced by Laflu were characterized using a metrologically valid procedure, with an associated uncertainty, and a statement of metrological traceability, following the guidelines from ISO Guide 31, providing the final user of these reference materials a wide range of relevant information to ensure quality in the measurement results that will be obtained.

The following topics offer a brief description of the equipment used in this study and the reason for their choice.

\subsubsection{Capillary viscometers}

Viscosity is a function of the viscometer constant and of the liquid flow time, in seconds, from the top line to the bottom line of the measurement bulb.

Capillary viscometers are used when measuring Newtonian fluids. The studied biodiesel, beef tallow biodiesel transesterified with ethanol, presented this behavior. The Ubbelohde viscometer is a suspended-level viscometer, with an uniform driving head of liquid, independent of the sample quantity inserted into the viscometer, making the viscometer constant independent of temperature. An Ubbelohde capillary viscometer type I (range of $2.0 \mathrm{~mm}^{2} / \mathrm{s}$ to $10.0 \mathrm{~mm}^{2} / \mathrm{s}$ ) (Fig. 4) was used for the studies.

This type of viscometer was chosen since international standards ISO EN 14214 and ASTM D 6751 indicate that biodiesels, to be considered in their specifications, must present viscosity between $3.0 \mathrm{~mm}^{2} / \mathrm{s}$ and $6.0 \mathrm{~mm}^{2} / \mathrm{s}$ at $40{ }^{\circ} \mathrm{C}$.

It is important to emphasize that the metrological traceability of capillary viscosimeters must be obtained from the attributed value for the viscosimeter constant calibrated at the nth step in the stepping-up procedure based on the absolute value of $1.0034 \mathrm{~mm}^{2} \mathrm{~s}^{-1}$ for the kinematic viscosity of distilled water at $20{ }^{\circ} \mathrm{C}$ (ISO 3104, ASTM D445-11 and ISO 3105) and the normal atmospheric pressure as stated in ISO TR 3666. 


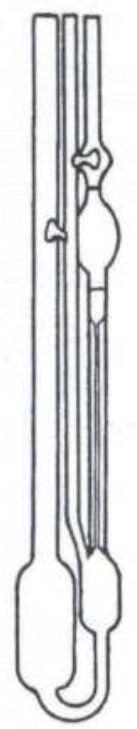

Fig. 4. Ubbelohde capillary viscometer.

\subsubsection{Digital density meters}

Density was measured with a digital density meter Anton Paar DMA 5000 (Fig. 5). The device is equipped with a vibration transducer for digital density meters which is able to indicate sample density when the fluid reaches its natural frequency.

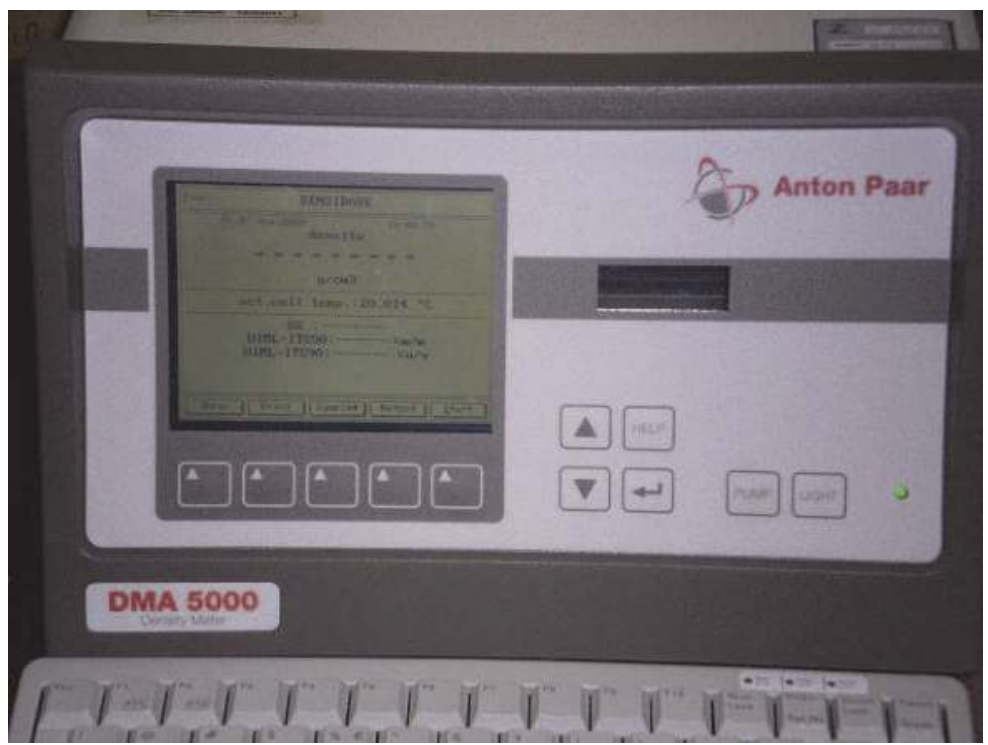

Fig. 5. Digital Density Meter. 
The reasons why density meters were chosen in this work over other measuring devices are explained as follows. Density meters have been used more frequently nowadays due to their simple operational procedures. They allow measurements to be performed with very small sample amounts compared to hydrometers, and they also provide fast results. Furthermore, the temperature of the measurement tube in which the fluid is placed can be changed very quickly, minimizing, in this way, the amount of time spent in replacing solutions and stabilizing bath temperatures.

The metrological traceability for this digital density meter was done in the temperature range of $4{ }^{\circ} \mathrm{C}$ to $40^{\circ} \mathrm{C}$ by the following solutions: n-nonane, mineral oil, and distilled water used as reference material which was measured by the hydrostatic weighing system, the primary method used in Brazil. Air density during the calibration was $0.00120 \mathrm{~g} / \mathrm{cm}^{3} \pm$ $0.00002 \mathrm{~g} / \mathrm{cm}^{3}$. The internal adjust factor is determined using distilled water and dry air.

\subsection{Production planning}

For this study, 79 samples of biodiesel were bottled in $50 \mathrm{~mL}$ glass bottle, amber colored with a sealed nitrilic lid, with the purpose of avoiding modification of the studied properties due to light incidence and to allow the withdrawal of the sample with a hypodermic syringe, so it will not contaminate the environment. Such methodology is fundamental for biodiesel samples, since they are known for having little hygroscopy and big oxidation (Knothe et al., 2005] with the environment, especially at higher temperatures.

According to ISO Guide 35, the steps for the homogeneity, stability and characterization tests were planned for the desired properties. For the aforementioned studies, the following temperatures were used: $4^{\circ} \mathrm{C}, 20^{\circ} \mathrm{C} \mathrm{e} 40{ }^{\circ} \mathrm{C}$; with $20^{\circ} \mathrm{C}$ being the reference temperature.

In order to establish the strategy for the homogeneity study, it is important to consider that a material is said to be homogeneous with respect to a property if this properties' value, when determined by testings with specific sized samples, is within uncertainty range, specified beforehand. Homogeneity is the condition of uniformity of a composition structure with respect to one or more specific properties. Homogeneity with respect to the determination of viscosity and density was evaluated employing variance analysis, and also evaluating the value of the measurement obtained within the specified uncertainty range. It is worth emphasizing that the chosen method to evaluate the reference material candidate's homogeneity presents proper repeatibility and sensitivity. Such parameters are fundamental so that the reference material producer is able to evaluate the variation of the production process, which, in this case, is related to producing a batch and choosing samples randomly in order to represent the whole batch in a correct homogeneity evaluation. It is noteworthy that what is known as a batch is a definite quantity of some commodity produced by one supplier at one time under conditions that are presumed uniform [ISO Guide 34 and 35].

One of the most important factors for a proper homogeneity evaluation of a produced batch of reference material is the number of samples to be selected. Considering ISO Guide 35, one may notice that the number of samples depends on the batch size, so the number of samples withdrew from such batch must be considered as a representation of the whole batch. The minimum number of randomly selected bottles must not be smaller than ten, usually between ten and thirty (ISO Guide 35, 2006). Twenty biodiesel bottles were randomly selected for the homogeneity evaluation. From the 20 analysed bottles, 10 were used for the kinematic viscosity evaluation at $40^{\circ} \mathrm{C}$ and 10 were used for the density evaluation at $20^{\circ} \mathrm{C}$, so the requirements from standards ASTM D 6751 and ISO EN 14214 are met, apart from the criteria established in ANP's Resolution $n^{\circ}$ 007, publish in March 19, 2008. 
In the same way as the homogeneity study, the stability evaluation was performed in order to evaluate the capacity of a product to maintain the value of a certain property within specified limits for a known and previously established period of time when stocked in specified conditions. It is important to emphasize that the degree of instability of the biodiesel was evaluated after being prepared. In this production planning two conditions were evaluated: storage conditions (long term: $20{ }^{\circ} \mathrm{C}$ for density and viscosity) and transport conditions of the materials (short term: $4{ }^{\circ} \mathrm{C}$ and $40{ }^{\circ} \mathrm{C}$ for density and viscosity).

It is worth emphasizing that the selected method to the stability evaluation of the reference material candidate presents adequate selectivity and reproducibility, since the samples were evaluated at different times. Upon finishing the studies, the reference material producer may not only guarantee the stability of the material, but is also capable of specifying its storage and transport conditions.

Considering ISO Guide 35, there are two long-standing approaches for the stability study: classic and isochronous (van der Veen 2001a, 2001b; ISO Guide 35]. To the short term stability evaluation of the material focusing on the viscosity as a parameter, the viability study planned for an evaluation using the classic approach. Such approach was chosen since the determination of the viscosity of the samples may not be made in repeatibility conditions, that is, according to the method established by the producer, only two samples may be studied each day. With this, 15 samples of the reference material candidate that were stored in the study temperatures were used, kept at different times (15, 30, 45, 60 and 90 days after the study had begun) and kept in the following temperatures: 6 samples kept at $\left((4.0 \pm 1.5){ }^{\circ} \mathrm{C}\right.$ and 9 kept at $\left.(40.0 \pm 1.5)^{\circ} \mathrm{C}\right)$ (Santo Filho, 2010a).

With respect to the short term stability evaluation focusing on the density as a parameter, 21 samples of the reference material candidate were submitted to the isochronous approach. The isochronous approach emphasizes that measurements must be made, as best as possible, with the smallest time gap. For such study, the storage periods were of 10, 30, 45, 60 and 90 days after the study had begun and the study temperatures were $\left((4.0 \pm 1.5){ }^{\circ} \mathrm{C}\right.$, $(20 \pm 1){ }^{\circ} \mathrm{C}$ and $\left.(40.0 \pm 1.5){ }^{\circ} \mathrm{C}\right)$. In each of these periods, a reference material candidate sample was stored in the study temperatures. In the end of the period, all samples were measured at the reference temperature of $\left((20 \pm 1){ }^{\circ} \mathrm{C}\right)$, simultaneously.

Following the stability evaluation of the reference material candidate, the long term stability studies were planned and executed, using the classic approach. The samples were stored and analyzed at the reference temperature of $\left((20 \pm 1){ }^{\circ} \mathrm{C}\right)$ for 360 study days for both parameters in question, being 12 samples for the viscosity parameter (Santo Filho, 2010c) and 7 samples of density.

To characterize the reference material candidate, the density and viscosity parameters must be found, regarding their intended usage for biodiesel (ANP 7, 2008). Viscosity characterization was made using a viscometer calibrated in the $20^{\circ} \mathrm{C}$ to $40{ }^{\circ} \mathrm{C}$ range, which was also the chosen range to make an analysis of density with kinematic viscosity possible and also enable, if needed, the dynamic viscosity for the studied biodiesel. To characterize density, a density meter was used, calibrated in the temperature range of $20{ }^{\circ} \mathrm{C}$ to $40{ }^{\circ} \mathrm{C}$, with $5{ }^{\circ} \mathrm{C}$ increments for each measurement. To the viability study, 4 bottles were randomly selected, being 2 for the determination of viscosity and 2 for density.

In general, Laflu used a capillary viscometer which has a measurement bulb (Fig. 6). This viscometer must be immersed in a thermostatic bath and have the flow time measured using a calibrated chronometer. 


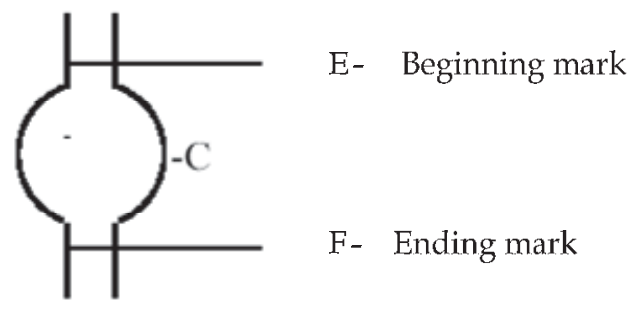

Fig. 6. Measurement bulb.

The viscometer with the reference material candidate for biodiesel had been immersed in a thermostatic bath until equilibrium temperature is reached. The thermostatic baths used were Lauda D-40 (as the main bath), with a Tamsom TLC-15 (as the fine tunning bath), controlled with $1 / 1000{ }^{\circ} \mathrm{C}$ precision thermometers. The testing temperatures were $20^{\circ} \mathrm{C}, 25$ ${ }^{\circ} \mathrm{C}, 30^{\circ} \mathrm{C}, 35^{\circ} \mathrm{C}$ and $40^{\circ} \mathrm{C}$. A time of at least $30 \mathrm{~min}$ is required for thermal equilibrium to be reached. During this period, the channels of the viscometer were protected from light to avoid any viscosity changes, such as oxidation.

Considering the density value, samples were placed into the digital density meter with the aid of a hypodermic syringe. The compartment that stores the samples is a U-shaped tube (Fig. 7). It is important to stress that care should be taken in avoiding bubbles when filling the tube since the presence of bubbles leads to incorrect readings. For each sample, at least four density readings were made for a given temperature value. The temperatures for the tests were $20^{\circ} \mathrm{C}, 25^{\circ} \mathrm{C}, 30^{\circ} \mathrm{C}, 35^{\circ} \mathrm{C}$ and $40^{\circ} \mathrm{C}$.

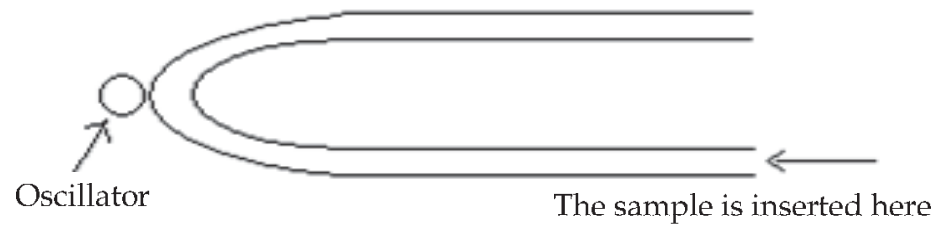

Fig. 7. U-shaped tube of digital density meter.

\section{Results obtained from the case study: Candidate refrence material for beef tallow biodiesel transesterified with ethanol}

\subsection{Homogeneity evaluation of samples}

Results from pure beef tallow biodiesel transesterified with ethanol are shown below and the guidelines of ISO Guide 35 were also applied. Table 1 and Fig. 8 shows the viscosity results from the randomly selected samples. Table 2 and Fig. 9 shows the density results from the randomly selected samples.

It can be observed that the results found through all the tests for each quantity are very close and are all placed within the range of the expanded uncertainty. With the variance analysis it was possible the find the uncertainty contribution regarding the homogeneity of the produced batch, considering the two analyzed parameters. The uncertainty regarding the homogeneity for density was $0.00004 \mathrm{~g} / \mathrm{cm}^{3}$ and for viscosity was $0.0006 \mathrm{~mm}^{2} / \mathrm{s}$.

The uncertainty values were found using equations 1 and 2. 


$$
S_{a}{ }^{2}=\frac{M Q_{\text {between }}-M Q_{\text {within }}}{n_{0}}
$$

And

$$
S_{b s}=\sqrt{S_{a}^{2}}
$$

where:

- $M Q_{\text {between }}$ is the squared average between samples

- $M Q_{\text {within }}$ is the squared average in each sample;

- $S_{b s}$ is the standard deviation between samples;

- $S_{a}^{2}$ is the variance between samples.

It is worth noting that the homogeneity uncertainty contribution for density was found considering the standard uncertainty of the measurement method.

\begin{tabular}{|c|c|}
\hline Sample & $\begin{array}{c}\text { Viscosity } \\
\left(\mathrm{mm}^{2} / \mathrm{s}\right)\end{array}$ \\
\hline 1 & 5.0261 \\
\hline 2 & 5.0277 \\
\hline 3 & 5.0266 \\
\hline 4 & 5.0263 \\
\hline 5 & 5.0273 \\
\hline 6 & 5.0264 \\
\hline 7 & 5.0277 \\
\hline 8 & 5.0269 \\
\hline 9 & 5.0264 \\
\hline 10 & 5.0259 \\
\hline
\end{tabular}

Table 1 . Homogeneity results of beef tallow biodiesel transesterified with ethanol viscosity, at $40{ }^{\circ} \mathrm{C}$.

\begin{tabular}{|c|c|}
\hline Samples & $\begin{array}{c}\text { Density } \\
\left(\mathrm{g} / \mathrm{cm}^{3}\right)\end{array}$ \\
\hline 1 & 0.86475 \\
\hline 2 & 0.86473 \\
\hline 3 & 0.86481 \\
\hline 4 & 0.86481 \\
\hline 5 & 0.86482 \\
\hline 6 & 0.86481 \\
\hline 7 & 0.86481 \\
\hline 8 & 0.86479 \\
\hline 9 & 0.86478 \\
\hline 10 & 0.86477 \\
\hline
\end{tabular}

Table 2. Homogeneity results of beef tallow biodiesel transesterified with ethanol density, at $20^{\circ} \mathrm{C}$. 


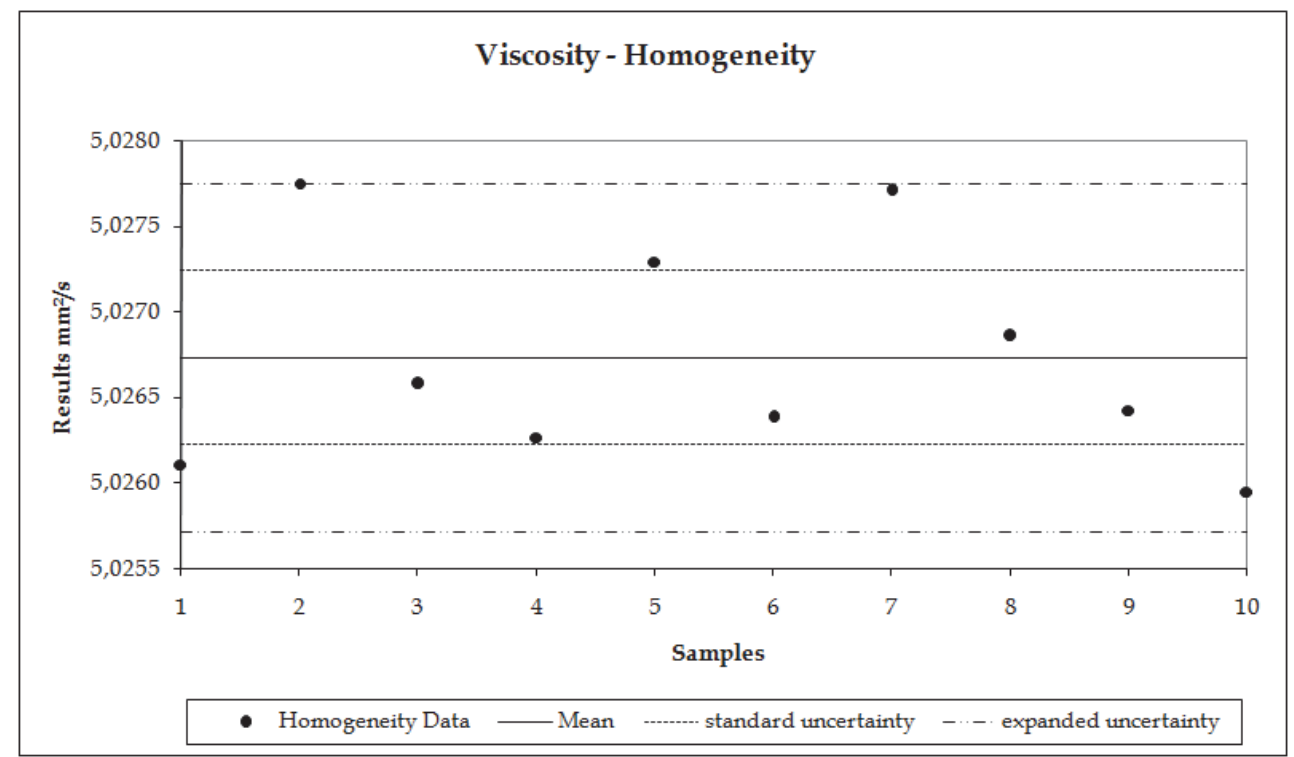

Fig. 8. Graph for homogeneity results of beef tallow biodiesel transesterified with ethanol viscosity, at $40^{\circ} \mathrm{C}$.

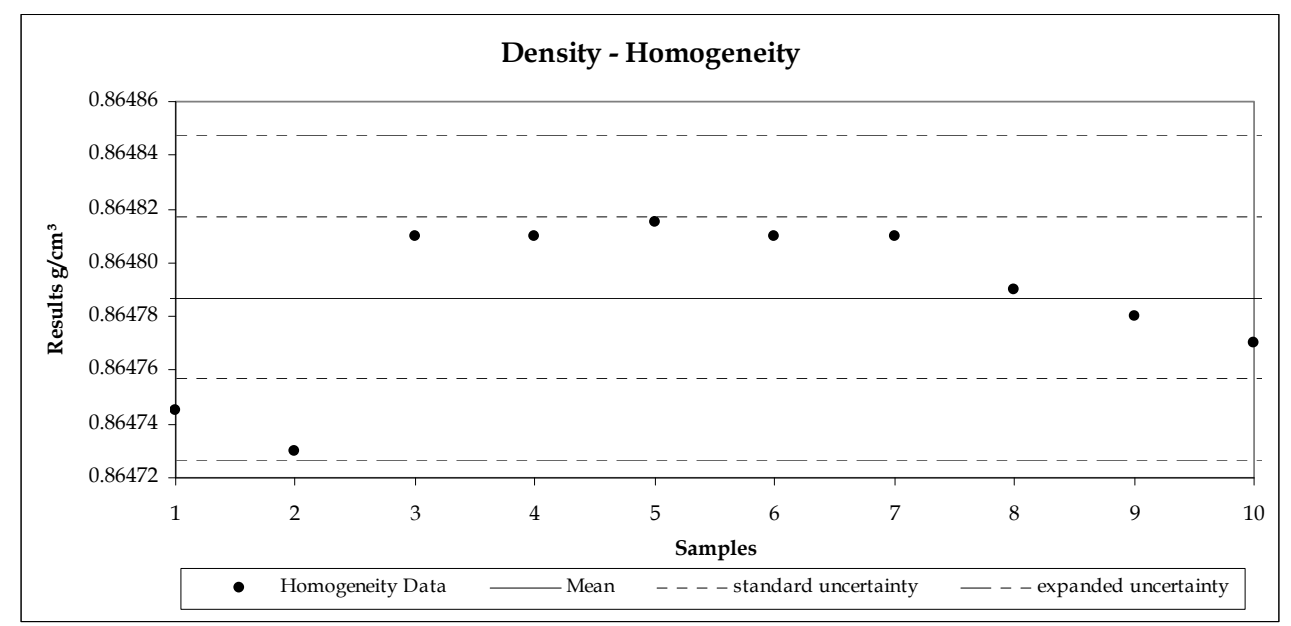

Fig. 9. Graph for homogeneity results of beef tallow biodiesel transesterified with ethanol density, at $20^{\circ} \mathrm{C}$.

\subsection{Stability evaluation of samples}

Results from pure beef tallow biodiesel transesterified with ethanol (Santo Filho 2010a, $2010 b$ ) are shown below and the guidelines of ISO Guide 35 were also applied. Fig. 10 shows 
the viscosity results from the randomly selected samples. Fig. 11 shows the density results from the randomly selected samples.

It can be observed that the results found through all the tests for each quantity were analyzed in a time period, applying different conditions of storage trying to evaluate the impact of temperature in transportation and storage of the reference material candidates.

Following the stability studies, the inclination of the curve, for all the measurements, was calculated using equation 3 (ISO Guide 35, 2006; Lisinger, 2001):

$$
b_{1}=\frac{\sum\left(X_{i}-\bar{X}\right)\left(Y_{i}-\bar{Y}\right)}{\sum_{i=1}^{n}\left(X_{i}-\bar{X}\right)^{2}}
$$

Where:

- $X_{i}$ is the time when the measurement was made;

- $\bar{X}$ is the average time for all measurements, in months (it is possible to use days or years, but, later, it must be converted to months);

- $Y_{i}$ is the viscosity, density measurements;

- $\bar{Y}$ is the average of all viscosity, density measurements.

This equation is found through the least mean square method (Taylor, 1997), and it is understood that the variation of viscosity and density is linear regarding time.

The inclination of the curve was calculated using equation (4):

$$
b_{0}=\bar{Y}-b_{1} \bar{X}
$$

The variance and the standard deviation were calculated using equations 5 and 6 (ISO Guide 35, 2006; Taylor, 1997, p.196-198.):

$$
\begin{aligned}
& s^{2}=\frac{\sum_{i=1}^{n}\left(Y_{i}-b_{0}-b_{1} X_{i}\right)^{2}}{n-2} \\
& s\left(b_{1}\right)=\frac{s}{\sqrt{\sum_{i=1}^{n}\left(X_{i}-\bar{X}\right)^{2}}}
\end{aligned}
$$

Meaning of the inclination of the curve from equation (7)

$$
\left|b_{1}\right|<\mathrm{t}_{0,95, \mathrm{n}-2} \cdot \mathrm{s}\left(b_{1}\right)
$$

Since the absolute value of $b_{1}$ was less than the product between the student's $t$ value (parameterized normal curve) with the standard deviation, it can be concluded that there was no relevant instability for the two studied properties.

The uncertainty regarding stability for density was $0.00009 \mathrm{~g} / \mathrm{cm}^{3}$ and for viscosity was $0.0008 \mathrm{~mm}^{2} / \mathrm{s}$. 


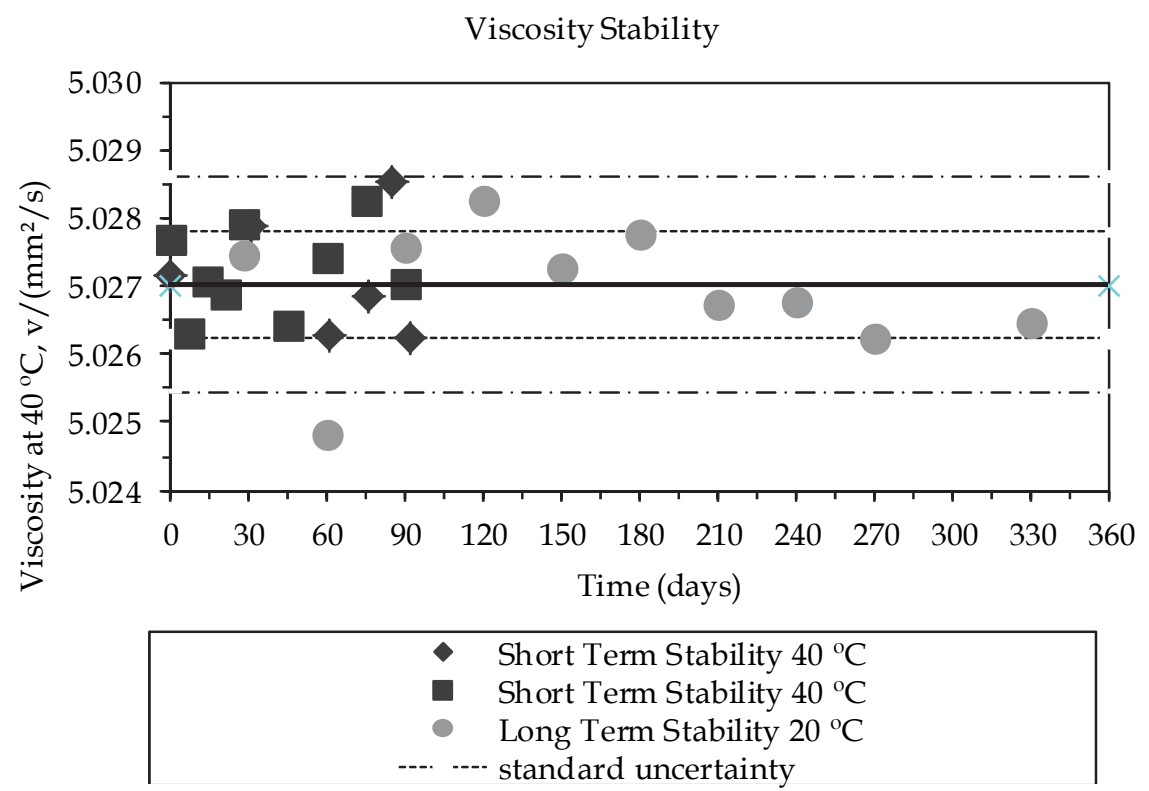

Fig. 10. Stability results of beef tallow biodiesel transesterified with ethanol viscosity, at $40^{\circ} \mathrm{C}$.

Density Stability

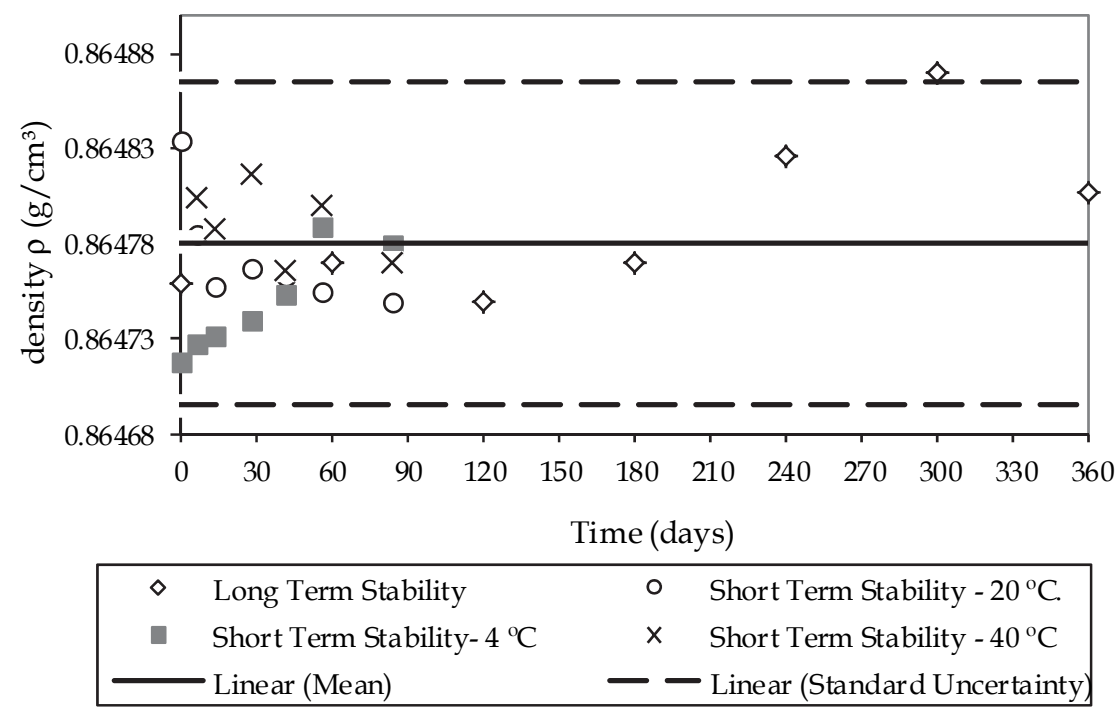

Fig. 11. Stability results of beef tallow biodiesel transesterified with ethanol density, at $20^{\circ} \mathrm{C}$. 


\subsection{Characterization of the produced reference material}

Table 3 shows the characterization of the beef tallow biodiesel's viscosity at $20{ }^{\circ} \mathrm{C}, 25^{\circ} \mathrm{C}$, $30^{\circ} \mathrm{C}, 35^{\circ} \mathrm{C}$ and $40^{\circ} \mathrm{C}$. The temperatures were studied with an Ubbelohde type I viscometer, which is Brazil's reference national standard (Santo Filho, 2009).

\begin{tabular}{|c|c|c|c|c|c|}
\hline Temperature & $\begin{array}{l}\text { Maximum } \\
\text { Viscosity }\end{array}$ & $\begin{array}{l}\text { Average } \\
\text { Viscosity }\end{array}$ & $\begin{array}{l}\text { Minimun } \\
\text { Viscosity }\end{array}$ & $\begin{array}{l}\text { Expanded } \\
\text { Uncertainty }\end{array}$ & \multirow{2}{*}{$\begin{array}{c}\text { Ubbelohde } \\
\text { Viscometer } \\
\text { Type }\end{array}$} \\
\hline $\begin{array}{c}\mathrm{T} \\
\left({ }^{\circ} \mathrm{C}\right)\end{array}$ & $\begin{array}{c}v_{\max } \\
\left(\mathrm{mm}^{2} / \mathrm{s}\right)\end{array}$ & $\begin{array}{c}v \\
\left(\mathrm{~mm}^{2} / \mathrm{s}\right)\end{array}$ & $\begin{array}{c}v_{\min } \\
\left(\mathrm{mm}^{2} / \mathrm{s}\right)\end{array}$ & $U$ & \\
\hline 20 & 8.2923 & 8.2830 & 8.2737 & 0.0093 & $\mathrm{I}$ \\
\hline 25 & 7.2329 & 7.2248 & 7.2167 & 0.0081 & I \\
\hline 30 & 6.3692 & 6.3620 & 6.3548 & 0.0072 & I \\
\hline 35 & 5.6740 & 5.6675 & 5.6610 & 0.0065 & I \\
\hline 40 & 5.0326 & 5.0269 & 5.0212 & 0.0057 & I \\
\hline
\end{tabular}

Table 3. Viscosity results for beef tallow biodiesel transesterified with ethanol, in a temperature measurement range of $20^{\circ} \mathrm{C}$ to $40^{\circ} \mathrm{C}$.

To determine the kinematic viscosity in each temperature it is necessary to calculate the measurement uncertainty of the kinematic viscosity measurement (Rodrigues et al., 2008 ; Barbosa et al., 2009). Since kinematic viscosity is measured indirectly, it must first be determined the mean flow time of the studied fluid, allowing then the calculation of the viscosity.

Regarding density, the viability study allowed the obtainment of the characterization data presented in tab. 4 . The reference material candidate samples of biodiesel were measured in a digital density meter.

The combined uncertainty is the squared sum of all the uncertainties of the input quantities. This result will provide the uncertainty of the measurand (i.e. quantity intended to be measured, according to VIM), which in this case is density. The expanded uncertainty is the combined uncertainty multiplied by a coverage factor, $k$. In this case $k$ is considered 2 , which means the results are in the range of two standard deviations.

\begin{tabular}{|c|c|}
\hline $\begin{array}{c}\text { Measurement } \\
\text { temperature }\end{array}$ & Liquid's calculated density \\
\hline${ }^{\circ} \mathrm{C}$ & $\mathrm{g} / \mathrm{cm}^{3}$ \\
\hline 20.00 & 0.86476 \\
\hline 25.00 & 0.86105 \\
\hline 30.00 & 0.85734 \\
\hline 35.00 & 0.85369 \\
\hline 40.00 & 0.85001 \\
\hline
\end{tabular}

Table 4. Density results for beef tallow biodiesel transesterified with ethanol, in a temperature measurement range of $20^{\circ} \mathrm{C}$ to $40^{\circ} \mathrm{C}$.

\subsubsection{Uncertainty of measurement estimates - approach used to assign uncertainties to the property values}

Studies for uncertainty of measurement estimates will be shown for the two physicalchemical quantities used for the characterization. 


\section{a) Viscosity equations and calculation of uncertainty of measurement}

The equations to determinate the viscosity of each measured are shown in equations 8 and 9 . Viscosity is a function of the viscometer constant and of the liquid flow time, in seconds, from the top mark to the bottom mark of the measurement bulb.

$$
\begin{gathered}
\nu=C_{1} \times\left(t-\frac{0.00166 \times \sqrt{V^{3}}}{C_{2} \times L \times \sqrt{C_{2} d}} \times \frac{1}{t^{2}}\right)+\beta \\
C_{1}=C_{2} \times\left\{\left[1+\alpha \times\left(T_{r}-T e m p\right) \times\left(\frac{\cos \phi_{1}}{\cos \phi_{2}}\right) \times\left(\frac{g_{1}}{g_{2}}\right) \times\left(1+\frac{2}{g_{1} h}\right) \times\left(\frac{1}{r_{u}}-\frac{1}{r_{l}}\right) \times\left(\frac{\sigma_{1}}{\rho_{1}}-\frac{\sigma_{2}}{\rho_{2}}\right)\right]\right\}
\end{gathered}
$$

Where:

$v$ is the kinematic viscosity $\left(\mathrm{mm}^{2} / \mathrm{s}\right)$;

$t$ is the flow time (s);

$C_{1}$ is the corrected constant of the calibrated viscometer $\left(\mathrm{mm}^{2} / \mathrm{s}^{2}\right)$;

$C_{2}$ is the constant of the calibrated viscometer $\left(\mathrm{mm}^{2} / \mathrm{s}^{2}\right)$;

$V$ is the volume of the flown liquid $\left(\mathrm{mm}^{3}\right)$;

$L$ is the capillary length $(\mathrm{mm})$;

$d$ is the capillary diameter ( $\mathrm{mm}$ );

$g_{1}$ is the acceleration of gravity at the measurement place $\left(\mathrm{m} / \mathrm{s}^{2}\right)$;

$g_{2}$ is the acceleration of gravity at the calibration place $\left(\mathrm{m} / \mathrm{s}^{2}\right)$;

OBS: In this study, $g_{1}$ and $g_{2}$ are considered equal because the place where the measurement took place is the same of the calibration.

$h$ is the hydrostatic pressure height $(\mathrm{m})$;

$r_{u}$ is the inner radius of the upper tube $(\mathrm{m})$;

$r_{l}$ is the inner radius of the lower tube $(\mathrm{m})$;

OBS: In practice, the variation of both these quantities is negligible.

$\sigma_{1}$ is the surface tension of the measured oil $(\mathrm{N} / \mathrm{m})$, in this study measured with a Krüss K100MK2 tensiometer;

$\sigma_{2}$ is the surface tension of the oil used in the calibration $(\mathrm{N} / \mathrm{m})$, in this study measured with a Krüss K100MK2 (N/m) tensiometer;

$\rho_{1}$ is the density of the measured oil $\left(\mathrm{kg} / \mathrm{m}^{3}\right)$, in this study measured with an Anton Paar DMA 4500 digital density meter;

$\rho_{2}$ is the density of the oil used in the calibration $\left(\mathrm{kg} / \mathrm{m}^{3}\right)$, in this study measured with an Anton Paar DMA 4500 digital density meter;

$\phi_{1}$ is the verticality angle in the measurement (close to zero);

$\phi_{2}$ is the verticality angle in the calibration (close to zero);

$T_{\text {emp }}$ is the measurement temperature $\left({ }^{\circ} \mathrm{C}\right)$;

$T_{r}$ is the reference temperature of the viscometer $\left({ }^{\circ} \mathrm{C}\right)$;

$\alpha$ is the glass volumetric thermal expansion coefficient $\left({ }^{\circ} \mathrm{C}^{-1}\right)$;

$\beta$ is the estimate of variation of the fluid's viscosity $\left(\mathrm{mm}^{2} / \mathrm{s} .{ }^{\circ} \mathrm{C}\right)$.

Note: The term $\beta$ is considered as $1 \%$ of the value of the measured viscosity multiplied by the value of the gradient of temperature from the characterized thermostatic bath. This value is used because there is a temperature gradient between the thermostatic bath's 
temperature and the studied oil's (in this case, biodiesel) temperature inside the viscometer. It is only considered for the calculation of the estimative of uncertainty of measurement. Mensurand: Kinematic Viscosity

$$
v\left(\frac{m m^{2}}{s}\right)
$$

Used instrument: Ubbelohde viscometer, type I;

Nominal measuring range:

$$
(2,0000-10,0000) \frac{m^{2}}{s}
$$

Therefore,

$$
v=f\left(C_{1}, t\right)
$$

Where:

$C_{1}$ is the viscometer constant $\left(\mathrm{mm}^{2} / \mathrm{s}^{2}\right)$;

$t$ is the fluid flow time, in the measured temperature (s).

$$
v=f\left(C_{1}, \alpha, t, \phi_{1}, \phi_{2}, g_{1}, g_{2}, h, r_{u}, r_{l}, \sigma_{1}, \sigma_{2}, \rho_{1}, \rho_{2}\right)
$$

For each input quantity, the sensibility coefficients must be calculated.

After the calculation of the sensitivity coefficients the items 4.2 and 4.3 from the ISO Gum must be used in order to determine whether the evaluations are Type A or Type B, respectively.

The Type A evaluation is based in a set of observations of $X i$, through a statistical treatment, and is usually obtained through the average between $n$ measurements, shown in (13):

$$
\bar{v}=\frac{1}{n} \sum_{k=1}^{n} v_{k}
$$

Where:

$\bar{v}$ is the arithmetic mean or average;

$n$ is the number measurements;

$v_{k}$ is the number of independent observations.

The other components, which may be evaluated by Type B evaluation of measurement uncertainty, can also be characterized by standard deviations, evaluated from probability density functions based on experience or other information.

All of the Type B evaluations of this study were considered rectangular, as shown in table 4 . Then, item 5.1.3 from the ISO Gum is used to obtain the combined standard uncertainty.

$$
u_{c}^{2}(v)=\sum_{i=1}^{N}\left[c_{i} \cdot u\left(x_{i}\right)\right]^{2} \equiv \sum_{i=1}^{N} u_{i}^{2}(v)
$$

And

$$
u_{i}(v) \equiv\left|c_{i}\right| \cdot u\left(x_{i}\right)
$$


And the degrees of freedom, obtained from the Welch-Satterthwaite formula, as in item G.4 from ISO Gum.

Where:

$$
v_{\text {eff }}=\frac{u_{c}^{4}(v)}{\sum_{i=1}^{N} \frac{u_{i}^{4}(v)}{v_{i}}}=\frac{u_{c}^{4}(v)}{\sum_{i=1}^{N} \frac{\left(u\left(x_{i}\right) \times c_{i}\right)^{4}}{v_{i}}}
$$

$N$ is the number of input quantities;

$v_{i}$ is the number of degrees of freedom for each quantity $X_{i}$.

OBS: It was considered that the number of degrees of freedom is infinite if the calculated degrees of freedom is higher than 500 .

A number $\mathrm{n}$ of measurements were made in the allotted time. With them, the standard deviation st can be calculated. The chronometer uncertainty $I_{t}$ is obtained from its calibration certificate. In the case that the coverage factor $k$ has not been declared, a rectangular distribution is considered. The combined standard uncertainty will then be:

$$
u_{c}(t)=\sqrt{\frac{s_{t}{ }^{2}}{n}+\left(\frac{I_{t}}{k}\right)^{2}}
$$

And the degrees of freedom

$$
v_{e f f}(t)=\frac{\left(u_{c}(t)\right)^{4}}{\frac{s_{t}^{4}}{n-1}}
$$

\section{b) Density equations and calculation of uncertainty of measurement}

The equation to determine the density of the liquid indicated in the digital density meter (ISO 15212-1:1998; ISO 15212-2:1998; ASTM D4052-09) is:

$$
\rho_{L i}=\rho_{a}-F_{v} \times\left(t_{v a}^{2}-t_{v L}^{2}\right)+\delta \rho_{a}+\delta \rho_{L}(T)+\delta R\left(\rho_{L}\right)+\delta D
$$

Where:

$\rho_{\mathrm{Li}}$ is the density of the liquid indicated in the digital density meter $\left(\mathrm{g} / \mathrm{cm}^{3}\right)$;

$\rho_{a}$ is the density of the air indicated in the digital density meter $\left(\mathrm{g} / \mathrm{cm}^{3}\right)$;

$F_{v}$ is the indicated value to determine the internal calibration factor $\left(\mathrm{g} / \mathrm{cm}^{3}\right)$;

$t_{v a}$ is the indicated value directly proportional to the oscillation period of the air;

$t_{v l}$ is the indicated value directly proportional to the oscillation period of the liquid;

$\delta \rho_{a}$ is the variation of the air density during the solution's measurement $\left(\mathrm{g} / \mathrm{cm}^{3}\right)$;

$\delta \rho_{L}$ is the variation of the liquid density;

$\delta R\left(\rho_{\mathrm{L}}\right)$ is the repeatability of measurements (random);

$\delta D$ is the Correction due to the fluid's damping (oscillation).

\subsection{Presentation of the final results}

Tables 5 and 6 show the calculations of the measurement uncertainty estimative of each quantity. The values are rounded to two significative digits of the uncertainty. 
The results were depicted assuming the associated uncertainty as a value of the viscosity and density properties as:

$$
u=\sqrt{\left(u_{\text {char }}\right)^{2}+\left(u_{b s}\right)^{2}+\left(u_{l t s}\right)^{2}+\left(u_{s t s}\right)^{2}+\left(u_{s t s 40}\right)^{2}}
$$

Where:

$u$ is the combined standard measurement uncertainty (or, the measured uncertainties in the usual metrological studies);

$u_{\text {char }}$ is the measurement uncertainty for the characterization;

$u_{b s}$ is the standard measurement uncertainty due to the (non) homogeneity between bottles;

$u_{l t s}$ is the standard measurement uncertainty due to the long term (in)stability;

$\mathrm{u}_{\mathrm{sts} 4}$ is the standard measurement uncertainty due to the short term (in)stability of the bottles that were stored in a freezer;

$\mathrm{u}_{\mathrm{sts} 40}$ is the standard measurement uncertainty due to the short term (in)stability of the bottles that were stored in a thermostatic bath or hot air oven.

\begin{tabular}{|c|c|c|c|}
\hline & $\begin{array}{c}\text { Average value } \\
\mathrm{mm}^{2} / \mathrm{s}\end{array}$ & $\begin{array}{c}\text { Standard Uncertainty } \\
\mathrm{mm}^{2} / \mathrm{s}\end{array}$ & Uncertainty (\%) \\
\hline Homogeneity & 5.0267 & 0.0006 & $0.01 \%$ \\
\hline Stability & 5.0269 & 0.0008 & $0.02 \%$ \\
\hline Characterization & 5.0269 & 0.0029 & $0.06 \%$ \\
\hline & $\begin{array}{c}\text { Average value } \\
\mathrm{mm}^{2} / \mathrm{s}\end{array}$ & $\begin{array}{c}\text { Combined } \\
\text { Uncertainty }(u) \\
\mathrm{mm}^{2} / \mathrm{s}\end{array}$ & $\begin{array}{c}\text { Combined } \\
\text { Uncertainty }(\%)\end{array}$ \\
\hline Declared value & 5.0269 & 0.0031 & $0.06 \%$ \\
\hline
\end{tabular}

Table 5. Summary of results for the viscosity of beef tallow biodiesel transesterified with ethanol, at a temperature of $40^{\circ} \mathrm{C}$.

\begin{tabular}{|c|c|c|c|}
\hline & $\begin{array}{c}\text { Average value } \\
\mathrm{g} / \mathrm{cm}^{3}\end{array}$ & $\begin{array}{c}\text { Standard Uncertainty } \\
\mathrm{g} / \mathrm{cm}^{3}\end{array}$ & Uncertainty (\%) \\
\hline Homogeneity & 0.86479 & 0.00004 & $0.004 \%$ \\
\hline Stability & 0.86478 & $0.00009^{*}$ & $0.010 \%$ \\
\hline Characterization & 0.86476 & 0.00004 & $0.005 \%$ \\
\hline & $\begin{array}{c}\text { Average value } \\
\mathrm{g} / \mathrm{cm}^{3}\end{array}$ & $\begin{array}{c}\text { Combined } \\
\text { Uncertainty }(u) \\
\mathrm{g} / \mathrm{cm}^{3}\end{array}$ & $\begin{array}{c}\text { Combined } \\
\text { Uncertainty }(\%)\end{array}$ \\
\hline Declared value & 0.86478 & 0.00010 & $0.01 \%$ \\
\hline
\end{tabular}

*: Long term stability valued was used

Table 6. Summary of results for the density of beef tallow biodiesel transesterified with ethanol, at a temperature of $20^{\circ} \mathrm{C}$.

With this, the biodiesel reference material candidate presented the following values to the studied properties and the associated uncertainties:

$$
v=(5.027 \pm 0.007) \mathrm{mm}^{2} / \mathrm{s}^{1}
$$




$$
\rho=(0.8648 \pm 0.0002) \mathrm{g} / \mathrm{cm}^{3}
$$

\section{Conclusions}

Considering the importance of the energy sector to the country, production and disponibilization of reference materials to this is of the utmost importance. Such reference materials have become extremely important for test laboratories that are responsible for issuing test reports with information regarding biofuels specification (Borges, 2007). As a National Metrology Institute, Inmetro aims towards production and certification of reference materials, assuring comparability and reliability of the measurement results.

The results presented in this chapter have demonstrated the possibility of producing a reference material aimed towards internal quality control of test laboratories that provide service to the Regulating Agency for Petroleum, Natural Gas and Biofuels (ANP - Agência Reguladora de Petróleo, Gás Natural e Biocombustíveis) from Brazil. The production of reference materials for quality control is preponderant when then reference materials present similarities to the samples that are usually handled in the laboratory and, mostly, when are no certified reference materials available. It is also possible to point out the application of the reference material as an homogenous and stable study subject to be used in proficiency studies carried out nationally or internationally. Such activities have great importance in assuring quality of the measurement results from Brazilian laboratories and are important tools to the Brazilian accreditation body, since the proficiency test reports allow relevant informations regarding the performance of accredited laboratories and those who wish to be accredited. Still as a conclusion for the viability study presented in this chapter, as an activity of the National Metrology Institute, the production of a certified reference material for biodiesel studies is possible following the used methodology. These certified reference materials could be used in the validation process of a method of a test laboratory, as it would allow the development of technical standards regarding biodiesel analysis. Following this approach, the certified reference materials could be used in a collaborative study to obtain parameters such as repeatibility and reproducibility limit to be used in the creating of Brazilian standards.

In conclusion, the studied biodiesel may be used as reference material for physical-chemical quantities (viscosity and density) in some cases, such as materials quality control (Dube, 2001) and to evaluate the performance of a laboratory that routinely analyses biofuels (Emons, 2006).

Biodiesels are not recommended for calibration of viscosity primary standards, such as capillary viscometers, since the variation of this property, in comparison to the same property in mineral oils (which are used as certified reference materials) is much greater. They are also not recommended to calibrate density devices such as digital density meters.

\section{Acknowledgement}

The authors would like to thank Eng. Felipe de Oliveira Baldner from Fluids Laboratory of Inmetro for the fruitful discussions.

The authors would also like to thank the Scientific Metrology Division of Inmetro (Dimci) for the financial support.

The author Roberto G. Pereira is grateful to the National Research Council of Brazil - CNPq for the financial support received. 


\section{References}

ANP's Resolution $n^{\circ}$ 007, AGÊNCIA NACIONAL DO PETRÓLEO, GÁS NATURAL E BIOCOMBUSTÍVEIS (ANP), publish in March 19, 2008.

ASTM D445 - 11 Standard Test Method for Kinematic Viscosity of Transparent and Opaque Liquids (and Calculation of Dynamic Viscosity).2011.

ASTM D4052 - 09 Standard Test Method for Density, Relative Density, and API Gravity of Liquids by Digital Density Meter.2009.

ASTM D6751 - 11 Standard Specification for Biodiesel Fuel Blend Stock (B100) for Middle Distillate Fuels.2011.

BARBOSA, A.P.F. et al., Metrological Approach in the Characterization of Viscosity of Corn Biodiesel Relative to Temperature, Using Capillary Viscometers. XIX IMEKO World Congress, Lisboa, Portugal, 2009.

Borges, R. M. H., Metrology as a laboratory instrument - The case of biofuels analysis laboratories "A METROLOGIA COMO UM INSTRUMENTO AOS LABORATÓRIOS - O CASO DE LABORATÓRIOS DE ANÁLISES DE COMBUSTÍVEIS", UFRJ, Escola de Química, 2007.

Dennehy, Peter. CONFORMITY ASSESSMENT and REGULATIONS \& THE ISO/CASCO TOOLBOX. WTO Workshop on CONFORMITY ASSESSMENT. Geneva, 16th -17 th March 2006.

Dube, G. Metrology in Chemistry - A public Task. Accreditation and Quality Assurance, 2001, 6:3-7.5p.

Emons, H. et al., New Definitions on Reference Materials. Accreditation and Quality Assurance, 2006, 10:576-578, 3p.

Emons, H. The 'RM family'-Identification of all of its members. Accreditation and Quality Assurance, 2006, 10:690-691.2p.

Hufbauer, G., Kotschwar, B., Wilson, J., Trade, standards and development; perspectives from Latin America, Washington, World bank, 2000.

Imai, H., Overall view of ISO REMCO Guides, RM producer accreditation training course, Tsukuba, Japan, 2007.

ISO Guide 31:2000. Reference materials - Contents of certificates and labels.

ISO Guide 34:2009.General Requirements for the Competence of Reference Material Producers, 2009.32p.

ISO Guide 35:2006.Reference Materials- General and Statistical Principles For Certification, 2006.64p.

ISO 3104:1994 - Petroleum products -- Transparent and opaque liquids -- Determination of kinematic viscosity and calculation of dynamic viscosity.

ISO 3105:1994 - Glass Capillary Viscometers Specification and Operating Instructions.

ISO EN 14214:2008 - Automotive Fuels - Fatty Acid Methyl Esthers (FAME) for diesel engines Requirements and test methods.

ISO 15212-1 Oscillation-type density meters - Part 1: Laboratory Instruments, First Edition, 199810-01.

ISO 15212-2 Oscillation-type density meters - Part 2: Process homogeneous liquids, First Edition, 2002-03-01.

ISO 17025:2005 - General requirements for the competence of testing and calibration laboratories.

ISO/TR 3666:1998. Viscosity of Water. 
JCGM 100:2008. Evaluation of measurement data - Guide to the expression of uncertainty in measurement.

KCDB - http://kcdb.bipm.org/AppendixC/M/BR/M_BR.pdf.

Knothe, G.; Van Gerpen, J. \& Krahl, J. The Biodiesel Handbook. ISBN: 1893997790. AOCS Press, 2005, 303p.

Lisinger, $\mathrm{T}$ et al., Homogeneity and stability of reference materials. Accreditation and Quality Assurance, 2001. 6:20-25 Springer-Verlag.6p.

Lyra, P.S.F. Diesel Engine: Injection, Lubrification, Combustion and Emissions "Motor Diesel: Alimentação, Lubrificação, Combustão e Emissões". Laboratório de Motores do Inmetro, 2008.96p.

Maggi, Patrick C et al., Final report on CCM.V-K2 comparison. Metrologia 46 07003, 2009.

Rodrigues, C.R.R. et al., Metrological Approach in the Variation Study of Soy Biodiesel Viscosity related to the temperature using a capillary viscometer" Abordagem Metrológica no Estudo da Variação da Viscosidade de Biodiesel de Soja com Relação à Temperatura, Utilizando-Se um Viscosímetro Capilar", I Mechanical Metrology Congress (Cimmec), Rio de Janeiro, 2008.

Santo Filho, D.M.E. et al., Viscosity Measurement of Cappilary Viscometers. SIM Metrology School. 2009, 40p.

Santo Filho, D.M.E., Metrology Applied to Biodiesel Analysis “METROLOGIA APLICADA À ANÁLISE DE BIODIESEL”, UFF, Engenharia Mecânica, PGMEC, 2010a.

Santo Filho, D.M.E. et al., Characterization of Density Of Biodiesel From Soybean, Sunflower, Canola and Beef Tallow in Relation to Temperature, Using a Digital Density Meter, With a Metrological Point of View. Journal of ASTM International, Vol. 7, No. 2 Paper ID JAI102430, 2010b.8p.

Santo Filho, D.M.E. et al., The Possibility of Using Beef Tallow Biodiesel as a Viscosity Reference Material. Accreditation and Quality Assurance. 10-3-2010, 2010c.4p.

Siqueira, J.R.R. - Accreditation of Reference Materials Producers - Profile Identification of Laboratories that Serve New Propostions “Acreditação de Produtores de Material de Referência - Identificação do Perfil de Laboratórios que Atendam às Novas Propostas", UFF, Engenharia de Produção, 2006.

Taylor, R.J. An Introduction to Error Analysis - The Study of Uncertainties in Physical Measurements. ISBN 978-0-935702-75-0 .Second Edition, University Science Books,1997.327p.

van der Veen A.; Lisinger T. \& Pauwels J. Uncertainty calculations in the certification of reference materials. 2. Homogeneity study. Accreditation and Quality Assurance 6:2630, 2001a.5p.

van der VEEN A et al. Uncertainty calculations in the certification of reference materials. 4. Characterisation and Certification. Accreditation and Quality Assurance 6:290-294, 2001b.5p.

VIM - International Vocabulary of Metrology - Basic and general concepts and associated terms JCGM 200-2008. 


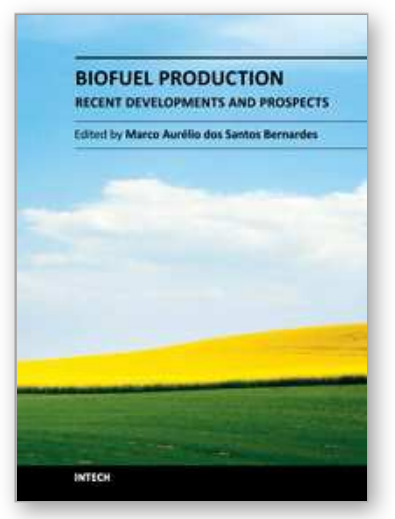

\section{Biofuel Production-Recent Developments and Prospects \\ Edited by Dr. Marco Aurelio Dos Santos Bernardes}

ISBN 978-953-307-478-8

Hard cover, 596 pages

Publisher InTech

Published online 15, September, 2011

Published in print edition September, 2011

This book aspires to be a comprehensive summary of current biofuels issues and thereby contribute to the understanding of this important topic. Readers will find themes including biofuels development efforts, their implications for the food industry, current and future biofuels crops, the successful Brazilian ethanol program, insights of the first, second, third and fourth biofuel generations, advanced biofuel production techniques, related waste treatment, emissions and environmental impacts, water consumption, produced allergens and toxins. Additionally, the biofuel policy discussion is expected to be continuing in the foreseeable future and the reading of the biofuels features dealt with in this book, are recommended for anyone interested in understanding this diverse and developing theme.

\section{How to reference}

In order to correctly reference this scholarly work, feel free to copy and paste the following:

Dalni Malta do E. Santo Filho, José Renato R. Siqueira, Renata Martins H. Borges, Claudio Roberto da C. Rodrigues, Alex Pablo F. Barbosa, José Júlio P. dos Santos Júnior and Roberto G. Pereira (2011). Is It Possible to Use Biodiesel as a Reference Material?, Biofuel Production-Recent Developments and Prospects, Dr. Marco Aurelio Dos Santos Bernardes (Ed.), ISBN: 978-953-307-478-8, InTech, Available from: http://www.intechopen.com/books/biofuel-production-recent-developments-and-prospects/is-it-possible-to-usebiodiesel-as-a-reference-material-

\section{INTECH}

open science | open minds

\author{
InTech Europe \\ University Campus STeP Ri \\ Slavka Krautzeka 83/A \\ 51000 Rijeka, Croatia \\ Phone: +385 (51) 770447 \\ Fax: +385 (51) 686166 \\ www.intechopen.com
}

\author{
InTech China \\ Unit 405, Office Block, Hotel Equatorial Shanghai \\ No.65, Yan An Road (West), Shanghai, 200040, China \\ 中国上海市延安西路65号上海国际贵都大饭店办公楼 405 单元 \\ Phone: +86-21-62489820 \\ Fax: $+86-21-62489821$
}


(C) 2011 The Author(s). Licensee IntechOpen. This chapter is distributed under the terms of the Creative Commons Attribution-NonCommercialShareAlike-3.0 License, which permits use, distribution and reproduction for non-commercial purposes, provided the original is properly cited and derivative works building on this content are distributed under the same license. 